\title{
Crítica dissensual: estética e densidade conceitual fren- te ao julgamento ético da intencionalidade artística
}

Francisco Dalcol*

\begin{abstract}
RESUMO: Propõe-se uma discussão teórica voltada a impasses da crítica com a virada social nas práticas artísticas e o esvaziamento dos critérios estéticos, problematizando uma tendência que toma a ética como valor e critério privilegiado para avaliar trabalhos processuais, desmaterializados, colaborativos e relacionais. Especula-se que tal abordagem tem caráter despolitizado se desconsiderar os antagonismos e a densidade conceitual em favor da intencionalidade dos artistas que usam situações sociais para produzir projetos participativos e/ou colaborativos. A partir de Néstor García Canclini, Hal Foster, Nicolas Bourriaud, Claire Bishop e Jacques Rancière, elabora-se uma compreensão do caráter crítico e político da arte como modo de operar uma crítica dissensual capaz de articular o estético sem sujeitá-lo ao julgamento ético.
\end{abstract}

PALAVRAS-CHAVE: crítica, estética, dissenso.

ABSTRACT: It proposes a theoretical discussion focused on the impasses of criticism with the social turn in the artistic practices and the emptying of the criteria of aesthetic, problematizing a tendency that takes ethics as value and criterion to evaluate process, dematerialized, collaborative and relational works. It is speculated that such an approach has a depoliticized character if one disregard antagonisms and conceptual density in favor of the intentionality of artists who use social situations to produce participatory and/or collaborative projects. From Néstor García Canclini, Hal Foster, Nicolas Bourriaud, Claire Bishop and Jacques Rancière, an understanding of the critical and political character of art is developed as a way of operating a dissensual critique capable of articulating the aesthetic without subjecting it to ethical judgment.

PALAVRAS-CHAVE: criticism, aesthetics, dissensus.

\footnotetext{
*Francisco Dalcol é crítico, pesquisador e curador independente. Doutorando em Artes Visuais - História, Teoria e Crítica pelo Programa de Pós-Graduação em Artes Visuais (PPGAV) da Universidade Federal do Rio Grande do Sul (UFRGS) - Bolsista Capes. Membro da Associação Brasileira de Críticos de Arte (ABCA) e da Associação Brasileira de Pesquisadores em Artes Plásticas (ANPAP).
} 
Em meio à dispersão da diversidade das práticas artísticas contemporâneas, há uma proliferação de projetos processuais, relacionais, colaborativos e desmaterializados que tomam o campo social como horizonte de atuação. São artistas que renunciam à produção de objetos artísticos para desencadearem processos de troca e colaboração com interesse no outro e na coletividade. Muitas dessas práticas fazem do espaço expositivo ou do site-specific o lugar privilegiado para a ativação de propostas abertas que se desenvolvem como laboratórios experimentais, ampliando noções de participação do público pela proposição de modelos de sociabilidade temporária. Esteticamente diferentes entre si, convergem no viés sociológico e político.

Ainda que tenham seus antecedentes na instalação, na performance, no happening e em outras experiências artísticas dos anos 1960 e 70 (ALBERRO, 2000), tais projetos artísticos se dão em um contexto diferente, da globalização contemporânea, no qual a arte é em grande parte definida, segundo Canclini, por dinâmicas e interações dentro e fora de seu próprio campo, em um processo de desdefinição que a torna pós-autônoma.

Com este termo, refiro-me ao processo das últimas décadas no qual aumentam os deslocamentos das práticas artísticas baseadas em objetos a práticas baseadas em contextos até chegar a inserir as obras nos meios de comunicação, espaços urbanos, redes digitais e formas de participação social onde parece diluir-se a diferença estética (CANCLINI, 2012, p. 24).

O entendimento da condição pós-autônoma da arte oferece um viés crítico para se analisar práticas de artistas que não têm a especificidade estética entre suas preocupações, mas a expansão da arte às zonas da vida social. Contudo, reivindicar uma compreensão do estético é tarefa necessária para se pensar os contornos que a reflexão crítica assume face aos critérios utilizados para tratar de projetos artísticos que agregam sujeitos em ações momentâneas e participativas e cujos interesses se voltam à coletividade, à participação e à colaboração.

A condição pós-autônoma da arte é acompanhada por um giro transdisciplinar na articulação entre os campos que envolve a redefinição do papel do artista, que passa a atuar como um produtor que leva em conta o processo de produção-circulação-consumo. Metodologias e procedimentos da etnografia e da antropologia se apresentam como ferramentas para um tipo de arte que se posiciona nos debates sobre identidade, alteridade e transculturalidade. Para Canclini, não se trata de um processo de convergência amigável: 
O giro transdisciplinar da arte, da antropologia e da sociologia configura uma situação do saber na qual entram em conflito a análise sobre processos estéticos que realizam estas ciências com experimentações desenvolvidas por artistas e com situações interculturais de circulação e de recepção. Mudam também os modos pelos quais as obras e as experiências artísticas são reinterpretadas ou disciplinadas pelas instituições que as expõem (CANCLINI, 2012, p. 49).

Quando comenta tais transformações globais e seu impacto na configuração do campo da arte em relação aos outros campos, Canclini considera artistas como León Ferrari, Antoni Muntadas, Santiago Sierra e Carlos Amorales, realizadores de propostas que incitam perguntas sociológicas e antropológicas cujos sentidos não se esgotam na materialidade das obras. São artistas que se apresentam como pesquisadores e pensadores ao tensionar os relatos dominantes, os consensos políticos e sociais, as relações entre os indivíduos e os modos de agrupamento.

Ainda nos anos 1990, Hal Foster já havia chamado a atenção para uma virada social na arte contemporânea com o interesse artístico pelas relações com a sociedade, a história, a economia e a política, expandindo o trabalho de arte em direção à pesquisa social e cultural. Em outras palavras, o campo havia se transformado em uma área transdisciplinar com forte influência das ferramentas e das metodologias próprias da antropologia. Sua análise propõe certo tipo de virada política, uma vez findada a era das utopias vanguardistas do projeto moderno. Como forma de iluminar essas práticas, Foster articula uma correlação ao mesmo tempo diacrônica e sincrônica: assim como as vanguardas históricas, as neovanguardas mantiveram em coordenação crítica os eixos vertical (temporal, a dimensão histórica da arte) e horizontal (espacial, a dimensão social da arte), enquanto que as práticas etnográficas na arte e nas teorias contemporâneas operaram uma expansão que privilegiou o eixo horizontal. Essa análise leva o autor a discutir o lugar das práticas artísticas a partir do que denomina de virada para o referente - a saber, uma virada das elaborações específicas do meio artístico para projetos artísticos no campo social.

Em sua argumentação, Foster retoma o texto "O autor como produtor", no qual Walter Benjamin exorta o artista de esquerda e politicamente engajado a se colocar ao lado do proletariado, decidindo a favor de qual causa colocará sua atividade como fundamento do seu progresso político (BENJAMIN, 1986, p. 120). Benjamin equiparava o artista avançado ao trabalhador revolucionário, ambos impelidos a intervir nos meios de produção (de arte ou de 
trabalho) como modo de transformação do "aparato" da cultura burguesa. Ao tomar a noção de autor como produtor, Foster desloca sua atividade do âmbito econômico/luta de classes para o social/disputas culturais, propondo que, na arte de ponta de esquerda, surgiu um novo paradigma, o do artista como etnógrafo: “É com a virada etnográfica na arte e na teoria contemporâneas (...) que a virada de elaborações específicas do meio para projetos específicos de debate torna-se tão pronunciada" (FOSTER, 2014, p. 9). Essa virada decorrida entre os anos 1980 e 90, salienta Foster, tem relação não com um desejo de revolução utópica de transformação da sociedade como em Benjamin, mas com as reações de viés multicultural e interdisciplinar contra a capitalização da cultura e a privatização geral da sociedade e da cultura operadas pelas políticas neoliberais.

Nesse novo paradigma (o artista como etnógrafo), o objeto da contestação ainda é em grande medida a instituição de arte capitalista-burguesa (o museu, a academia, o mercado e a mídia), suas definições excludentes de arte e artista, identidade e comunidade. Mas o sujeito da associação mudou: é o outro cultural/étnico, em nome de quem o artista engajado mais frequentemente luta. (...) Apesar de sutil, esse desvio de um sujeito definido em termos de relação econômica para um sujeito definido em termos de identidade cultural é significativo (FOSTER, 2014, p. 160).

A teorização de Foster é chave para a problematização das relações da arte com um outro social ou étnico e para se analisar de forma crítica posicionamentos de artistas membros de classes e/ou lugares de fala privilegiados que se voltam a culturas e extratos sociais diferentes. Trata-se de algo que Benjamin já havia alertado em seu texto ao dizer que, mesmo engajado socialmente, o intelectual não é o proletário - embora, paradoxalmente, seja a condição de intelectual que o coloque em posição que permita reconhecer a exploração a que o proletário está submetido. Se por um lado há um deslocamento da relação econômica para a identidade cultural que distingue o autor como produtor do artista como etnógrafo, por outro lado alguns pressupostos do modelo de Benjamin persistem no paradigma do etnógrafo, mas de modo problemático. Segundo Foster: 1) o lugar da transformação política é também o lugar da transformação artística; 2) esse lugar está sempre em outra parte, no campo do outro - no modelo do autor como produtor, o outro social, o proletariado explorado; no paradigma do etnógrafo, o outro cultural, o pós-colonial, o oprimido; 3) se o artista invocado não é visto como outro social e/ou cultural, seu acesso a essa alteridade transformadora é limitado; mas, se é visto como 
esse outro social e/ou cultural, tem acesso automático à alteridade. Tal conjunto de pressupostos coloca o artista etnógrafo frente aos riscos do mecenato ideológico, verificado, por exemplo, em projetos que, somente pelo fato de envolverem ativismo social como intenção artística, já são previamente avaliados como críticos.

Ao abordar os novos lugares das práticas artísticas e políticas, Foster adensa a questão da alteridade e do outro cultural no paradigma etnográfico, discutindo a projeção desse outro-fora. A alterização nas práticas etnográficas é tratada sob o aspecto da alterização do eu, problematização fundamental para os modelos críticos na antropologia, na arte e na política. Foster chama atenção para os perigos da autoabsorção, na qual o projeto de uma automodelagem etnográfica se converte na prática de uma autorrestauração narcisista (FOSTER, 2014, p. 168). Tais problemáticas envolvendo a alteridade e a projeção desse outro-fora devem ser lidadas, argumenta Foster, com a reflexividade, embora ela não ofereça garantias de práticas críticas.

No mesmo período em que Foster investigava a relação entre os retornos de práticas históricas e as viradas nos modelos teóricos e críticos para iluminar determinadas práticas que ele identificava nos anos 1990, Nicolas Bourriaud publicava os ensaios que em 1998 seriam reunidos no livro Estética relacional. Sua tese é que a arte relacional "toma como horizonte teórico a esfera das interações humanas" (BOURRIAUD, 2009, p. 19). O crítico e curador francês se baseia na possibilidade de a arte relacional propor situações de encontro entre arte e público em condições de agregar sujeitos em ações momentâneas e participativas, especialmente por interações suscitadas no espaço de apresentação da obra. O conceito se vincula a trabaIhos que se valem de processos colaborativos e interativos e que procuram eliminar a distinção entre o artista produtor de objetos e os espectadores enquanto consumidores de imagens. Em seus ensaios, Bourriaud trata de artistas como Rirkrit Tiravanija, Liam Gillick, Pierre Huyghe, Maurizio Cattelán, Vanessa Beecroft, Carsten Höller, Dominique Gonzalez-Foerster e Philippe Parreno. São todos nomes que, em comum, realizam trabalhos abertos e instáveis, muitas vezes em colaboração, como projetos work-in-progress ou temporadas de residência.

Ao apontar nessas práticas artísticas a invenção de modos de sociabilidade a partir da ênfase na esfera da interação, Bourriaud ergueu a defesa de um modo diferenciado de inserção do espectador no contexto da obra. Assim, noções interativas, conviviais e relacionais foram convocadas para tratar de uma vertente artística interessada em experimentações sociais "como 
um espaço parcialmente poupado à uniformização dos comportamentos" (BOURRIAUD, 2009, p. 13). Bourriaud argumenta que, em vez de uma relação individual entre o trabalho de arte e o observador, a arte relacional estabelece situações em que se dirige aos observadores não apenas como uma entidade social e coletiva, mas de modo que a eles são dados os meios para criar uma comunidade, por mais temporário ou utópico que isso venha a ser. 0 aspecto interativo, argumenta o autor, é físico no sentido de ser uma resposta às relações virtuais da internet e da globalização que, por um lado, estimularam um desejo por interações mais físicas e interações cara a cara entre as pessoas e, por outro lado, inspiraram artistas a adotar uma abordagem faça-você-mesmo em relação ao público. É o que Bourriaud chama de "aprender a habitar o mundo" ao invés de construí-lo pela ideia pré-concebida de evolução histórica: "[...] as obras já não perseguem a meta de formar realidades imaginárias ou utópicas, mas procuram construir modos de existência ou modelos de ação dentro da realidade existente, qualquer que seja a escala escolhida" (BOURRIAUD, 2009, p. 18).

Essas ideias estabelecem uma série de proximidades com o que se observou em práticas dos anos 1960 e 70, mas Bourriaud se esforça para distanciar os trabalhos contemporâneos daqueles das gerações anteriores. Para isso, aponta uma mudança de atitude como resposta às alterações sociais e de uma economia baseada em bens para uma economia de serviços: em vez de uma agenda utópica, os artistas buscam soluções provisórias; em vez de transformar o mundo, desejam habitá-lo melhor; em lugar de utopias do futuro, intentam microutopias do presente. E é a partir desse diagnóstico que o autor se lança a formular o significado político da estética relacional: "a arte contemporânea realmente desenvolve um projeto político quando se empenha em investir e problematizar a esfera das relações" (BOURRIAUD, 2009, p. 23).

Com sua estética relacional, Bourriaud se lança a redefinir a crítica de arte contemporânea argumentando que os anos 1990 trouxeram um impasse causado em grande parte pela falta de disposição dos críticos em deixar de abordar os trabalhos por meio da história da arte e dos valores dos anos 1960 e 70. A solução demandaria novos critérios como os da arte relacional, de modo a dar conta de um tipo de arte que busca estabelecer encontros interssubjetivos em que o sentido é elaborado coletivamente.

Desde que ganhou espaço nos debates teóricos sobre a crítica, a estética relacional foi alvo de reações que apontaram sua despolitização ao refutar o antagonismo, as hierarquias e as 
oposições no campo social. Bourriaud parece precipitado ao argumentar que a arte relacional é uma forma social capaz de produzir relações humanas positivas. Ao defender a empatia, o apaziguamento dos confrontos e a coabitação comunitária, sua argumentação sugere que a interatividade da arte relacional gera por si democracia e emancipação. Canclini elabora a seguinte crítica:

Nesta recomposição mundializada, a estética relacional aparece como uma "reformulação apressadinha" de um crítico-curador interessado em intervir espetacularmente na crise analítica da arte com um repertório enviesado de obras e sem se encarregar da complexidade social (CANCLINI, 2012, p. 146).

No texto "Antagonismo e estética relacional," publicado em 2004 na revista October ${ }^{1}$, Claire Bishop elabora uma contundente crítica a Bourriaud. A pesquisadora inglesa reconhece que a arte relacional é um ponto de partida para se discutir os parâmetros de avaliação de projetos artísticos que se dedicam à coletividade, à colaboração e ao compromisso social. Entretanto, adensa pontos desconsiderados pela teoria relacional. Um deles parte da análise do trabalho de Rirkrit Tiravanija. Bishop comenta que os projetos desmaterializados de Tiravanija, híbridos de instalação e performance abertos ao estilo laboratório, revivem estratégias críticas dos anos 1960 e 70, mas apenas reproduzindo-as acriticamente, uma vez que não questionam a lógica do modelo econômico dominante que condiciona o contexto em que os trabalhos são apresentados. Outro exemplo vem de Liam Gillick, artista interdisciplinar que opera com esculturas, instalações e design gráfico. Bishop reconhece em suas obras heranças do legado da escultura minimalista e da instalação pós-minimalista, mas identifica uma clara oposição:

(...) enquanto as caixas modulares de Judd faziam com que o observador percebesse seu movimento corporal em torno do trabalho, ao mesmo tempo em que também chamavam a atenção para o espaço em que estavam expostos, para Gillick basta que os observadores "dêem as costas para o trabalho e conversem uns com os outros". Em vez de o observador "completar" o trabalho, à maneira dos corredores de Bruce Nauman ou as videoinstalações de Graham em 1970, Gillick busca uma abertura perpétua em que sua arte seja um pano de fundo para outras atividades (BISHOP, 2011, p. 116).

No âmbito da teoria relacional, Bishop critica a qualidade das relações produzidas, na medida em que a noção de presença física do visitante, que em muitas das práticas dos anos 1960 e 70 era parte constitutiva das obras, na arte atual transforma-se muitas vezes apenas em 
uma encenação próxima ao espetáculo e ao entretenimento. Assim, para a autora, as obras relacionais que facilitam diálogos não hierarquizados, assumindo-se como democráticas e éticas, não seriam políticas, além de correrem o risco de realizarem uma retomada acrítica das práticas antecedentes ao se instalar em espaços de agenciamento ou intercâmbio habitados pelos mesmos e iguais visitantes do espaço especializado da arte. Conjuntamente ao estatuto dessas relações, Bishop problematiza a ausência de questionamento do contexto em que elas se dão e a que finalidade possam atender.

\footnotetext{
A qualidade das relações em "estética relacional" nunca é examinada ou colocada em questão. Quando Bourriaud afirma que "encontros são mais importantes que os indivíduos que os compõem", percebo que essa questão (para ele) é desnecessária; todas as relações que permitem "diálogo" são automaticamente presumidas democráticas e, portanto, benéficas. Mas o que "democracia" de fato significa nesse contexto? Se a arte relacional produz relações humanas, então a próxima pergunta lógica a se fazer é quais tipos de relações estão sendo produzidas, para quem e por que (BISHOP, 2011, p. 120).
}

Bishop propõe que as relações sejam problematizadas no interior de práticas artísticas a partir dos antagonismos e das tensões. Valendo-se das ideias de Ernesto Laclau e Chantal Mouffe, que ajudam a pensar uma teoria de democracia como antagonismo, Bishop afirma que uma sociedade democrática é aquela em que os antagonismos e os conflitos não desaparecem e cujas fronteiras e horizontes políticos estão permanentemente sendo revistos e colocados em debate. O contrário é uma sociedade em que o antagonismo é obliterado por um consenso imposto e autoritário, tendo como consequência a supressão da discussão e dos próprios princípios de participação democrática. Nesse sentido, a permanência de antagonismos não pressupõe a retirada da utopia do campo do político, mas a sustentação da possibilidade de um imaginário radical.

De modo a exemplificar suas críticas à teoria de Bourriaud, Bishop analisa dois artistas que considera uma espécie de antítese da estética relacional: Thomas Hirschhorn e Santiago Sierra. As questões propostas por seus trabalhos problematizam relações e contextos sem reconciliações harmoniosas, sustentando tensões que encontram uma dimensão política.

Esses artistas estabelecem "relações" que enfatizam o papel do diálogo e da negociação em sua arte, mas o fazem sem que essas relações sucumbam ao conteúdo do trabalho. As relações 
produzidas por suas performances e instalações são marcadas por sensações de mal-estar e desconforto, em vez de pertencimento, porque os trabalhos reconhecem a impossibilidade de uma "microutopia" e, em vez disto, sustentam uma tensão entre observadores, participantes e contexto. Parte integrante dessa tensão é a introdução de colaboradores de realidade econômica distinta que, por sua vez, servem para desafiar a percepção da arte contemporânea como um domínio que engloba outras estruturas sociais e políticas (BISHOP, 2011, p. 125).

Com propostas bastante incisivas e subversivas, Hirschhorn e Sierra são autores de situações em que o público não é obrigado a participar literalmente, mas solicitado a ser um visitante reflexivo e pensativo. O espectador não é coagido a cumprir exigências interativas como na arte relacional, passando a ser visto como um sujeito de pensamento independente, o que oferece um pré-requisito para uma ação política e um pensamento crítico em arte.

Outro aspecto criticado por Bishop na teoria relacional é a argumentação de que trabalhos de arte abertos e participativos solicitam critérios éticos para o julgamento das relações produzidas, abrindo mão de critérios estéticos. Tal questão é em si sintomática de uma tendência da crítica contemporânea frente aos impasses do esvaziamento dos critérios de juízo estético, gerando um vácuo que parece ter sido preenchido por valores morais e éticos encontrados na intencionalidade do artista. Para Bishop, exemplares de estética relacional só podem ser eventualmente considerados criticamente políticos, como Bourriaud deseja, ao se analisar de que modo a arte contemporânea se dirige ao observador e ao se avaliar a qualidade das relações que produz. Assim, é preciso considerar que a ativação do público não é em si uma operação suficiente para configurar um ato democrático.

O antagonismo relacional a que me refiro não seria baseado na harmonia social, mas na exposição daquilo que é reprimido ao se sustentar uma aparência de harmonia. Ele, portanto, proveria bases mais concretas e polêmicas para repensar nossa relação com o mundo e uns com os outros (BISHOP, 2011, p. 132).

Defensores das práticas relacionais podem argumentar que as obras participativas desalienam uma sociedade entorpecida e fragmentada pela instrumentalidade do capitalismo. Contudo, tal entendimento político leva a uma situação na qual tais práticas colaborativas são automaticamente percebidas como gestos artísticos críticos e engajados. Por isso, torna-se crucial discutir, analisar e comparar criticamente os trabalhos enquanto arte, discutindo o efeito social e a qualidade artística. Nesse sentido, a virada social na arte contemporânea teria incitado 
uma virada ética que demonstra certa crise de parâmetros teóricos e conceituais para a crítica da arte. Como Bishop argumenta,

(...) os artistas estão sendo crescentemente julgados por seus processos de trabalho - o grau em que eles suprem bons ou maus modelos de colaboração - e criticados por qualquer sinal de possível exploração que falhe em representar "completamente" seus temas, como se isso fosse possível. Tal ênfase no processo em detrimento do produto (ou seja, meios sobre fins) é justificada por sua oposição à predileção do capitalismo pelo contrário (BISHOP, 2008, p. 148).

Nessa virada dos modelos críticos, o significado artístico de determinados projetos é deixado de lado em favor da avaliação não só da intencionalidade do artista, mas também da sua relação com seus colaboradores, das recompensas criativas da colaboração e da renúncia autoral. Esse direcionamento tem feito com que uma compreensão ética dos trabalhos seja privilegiada em detrimento da discussão sobre a densidade conceitual e estética. Como efeito, uma vertente crítica parece se contentar em avaliar a qualidade das obras pelo modo como funcionam no nível da intervenção social, muitas vezes confundindo-se com práticas ativistas e de inclusão social. Como consequência, Bishop identifica cisões entre produção e crítica:

E isto pode explicar, em algum grau, por que a arte socialmente engajada se libertou muito da crítica artística. A ênfase é deslocada da especificidade desagregadora de uma dada obra para um conjunto generalizado de preceitos morais (BISHOP, 2008, p. 150)

Bourriaud respondeu às críticas de Bishop em algumas ocasiões. No texto "Estética relacional, a política das relações", publicado no catálogo dos seminários da $27^{a}$ Bienal Internacional de São Paulo em 2006, o autor defende sua teoria relacional das acusações de que implicaria despolitização por meio da empatia e da coabitação comunitária. Bourriaud argumenta que uma obra deve ser avaliada por ela mesma e que, como crítico, não produz o seu significado a priori. Também toma posicão na discussão entre julgamento ético e estético descomprometendo-se com a intencionalidade artística.

O julgamento ético diria respeito à intenção do artista, e no meu papel de crítico não estou aqui para julgar intenções. Muitas vezes, a intenção é assimilada como conteúdo. O fato de um artista declarar que é engajado em uma causa, para mim, não é crucial para o significado do trabalho. Certamente, isso influencia a interpretação que podemos fazer dele; é claro que é parte do trabalho, mas não é o conteúdo em si (BOURRIAUD, 2008, p. 335). 
No mesmo texto, Bourriaud argumenta que a única maneira de a ética participar do julgamento estético na teoria relacional é pelo o que chama de "critérios de coexistência", defendendo a seguir que qualquer obra de arte produz uma imagem de valores sociais. Também oferece uma resposta à acusação de negar o contexto e a qualidade das relações entre artistas e público argumentando que a realidade social é produto de negociação e que a democracia é uma montagem de formas. Por fim, afirma que o valor político da arte "também reside em mostrar a precariedade do mundo, não representando esta precariedade, mas induzindo-nos a pensar que as sociedades em que vivemos hoje não são versões definitivas da realidade" (BOURRIAUD, 2008, p. 337).

A discussão articulada entre os textos e autores até aqui referidos pode ser adensada com a teoria elaborada por Jacques Rancière sobre arte e política. Inicialmente, é preciso reconhecer que as formulações desenvolvidas em especial por Claire Bishop apontam fecundos diálogos com a teorização de Rancière. São os casos, por exemplo, das aproximações entre as noções de antagonismo e dissenso e também da compreensão de que o caráter crítico e político da arte deve ser problematizado no interior das práticas artísticas, e não fora. Contudo, o filósofo francês oferece uma reflexão maior sobre o âmbito do estético na arte contemporânea, algo que não encontramos com o mesmo aprofundamento nos textos da pesquisadora inglesa.

Rancière pensa o estético não como uma teoria da arte sobre a sensibilidade ou o gosto, mas como um modo de ser específico das artes, daquilo que pertence ao modo de ser de seus objetos e sujeitos. A estética é, assim, um regime específico do sensível; de identificação e pensamento das artes: um modo de articulação entre maneiras de fazer e os modos de pensabilidade de suas relações. O regime estético identifica a arte no singular e afirma essa singularidade ao desobrigá-la de regras específicas; funda sua autonomia e articula essa autonomia numa espécie de devir que intervém na partilha do sensível; e mobiliza a configuração da experiência sensível com novos modos de sentir e novas formas de subjetivação política.

Ao mesmo tempo, a estética, diz Rancière, está na base da política, esta entendida não como exercício de poder, mas como conflito de objetos e sujeitos. Dito de outro modo, a arte e política têm a ver não por oferecer mensagens ou representações, mas formas de dissenso como operações de reconfiguração da experiência comum do sensível. O regime estético da 
política, que é a democracia, passa então a ser entendido de dois modos - como construção de consensos ou como trabalho de desacordos. Assim, a experiência estética toca a política porque também se define como experiência do dissenso. Se a arte pode ser uma força crítica que se apropria de valores e os redistribui, ela o fará por meio de dissensos, que têm a potencialidade de expor a desconstrução dos mecanismos com que operam os consensos dominantes. Assim, o estético, para Rancière, é a habilidade de pensar uma contradição no relacionamento da arte com o social.

É pois evitando as visões conciliadoras que a política pode ser redefinida no regime estético, na medida em que seja uma política que introduza sujeitos e objetos novos, tornando visível o oculto e escutando os silenciados. Assim, estética e política se articulam para dar visibilidade ao escondido, reconfigurando a divisão do sensível e tornando o dissenso evidente (RANCIÈRE, 2005, p. 2012). Nesse sentido, Rancière oferece aportes à reflexão crítica sobre a arte que se dedica a restabelecer ou a reinventar laços sociais como na teoria relacional de Bourriaud. A respeito disso, Canclini comenta:

Rancière rechaça a arte relacional destinada a remendar o vínculo social, construir miniespaços de sociabilidade, como esses programas oficiais que tendem a colocar no mesmo plano arte, cultura e assistência. Propõe, por outro lado, reconfigurar a divisão do sensível sobre a qual se simula o consenso, reedificar o espaço público dividido, restaurar competências iguais (CANCLINI, 2012, p. 137).

Para Rancière, a eficácia da arte não estaria voltada à transmissão de comportamentos e conteúdos engajados ao espectador para torná-lo atuante e consciente, fazendo-o tomar posição. Em lugar de uma arte política, há uma política da arte que implica a experiência estética em uma política que lhe é própria: a saber, um jogo de significação que fica em suspenso entre a intenção do artista e a compreensão do espectador. Ou seja: por mais que artistas intencionem, não se pode antecipar ou determinar o exato efeito de uma obra artística. Essa política da arte, ao invés de forjar explicações do mundo e criar relações no espaço social, tem como potencial reconfigurar a esfera do sensível a partir das experiências de cada um, do artista ao espectador:

(...) a eficácia da arte não consiste em transmitir mensagens, dar modelos ou contramodelos de comportamento ou ensinar a decifrar representações. Ela consiste sobretudo em disposições 
de corpos, em recorte de espaços e tempos singulares que definem maneiras de ser, juntos ou separados, na frente ou no meio, dentro ou fora, perto ou longe (RANCIÈRE, 2012, p. 55).

Por eficácia, Rancière entende o modelo do dissenso como cerne da política, no sentido de conflito que envolve diferentes regimes de sensorialidade: "se a experiência estética toca a política, é porque também se define como experiência de dissenso, oposta à adaptação mimética ou ética das produções artísticas com fins sociais" (RANCIĖRE, 2012, p. 60). Nessa compreensão, a arte é crítica quando seu efeito político passa pela distância estética, um efeito que, todavia, não pode ser garantido porque comporta uma parcela do indecidível.

Há, assim, uma política da arte que precede as políticas dos artistas, uma política da arte como recorte singular dos objetos da experiência comum, que funciona por si mesma, independentemente dos desejos que os artistas possam ter de servir a esta ou aquela causa (RANCIÈRE, 2012, p. 63).

Pensar o regime estético nos termos de Rancière oferece um instrumental teórico para lidar com os impasses nos critérios de avaliação encontrados na crítica de arte que privilegia a ética do artista. Confrontar valores de intencionalidade face à densidade conceitual dos trabalhos artísticos pode ser um caminho para que a crítica se reabilite na contemporaneidade sem perder de vista o estético como específico e próprio a uma política do sensível. Para isso, faz-se necessária a compreensão de que, se a experiência estética toca a política, é porque também se define como experiência do dissenso, de subversões dos elos sociais, de deslocamento e embaralhamento das linhas de separação dos consensos que constróem a realidade.

Tais noções desenvolvidas por Rancière formulam uma crítica dissensual capaz de articular o estético sem sujeitá-lo ao julgamento ético, valorizando a singularidade das operações artísticas que abrem passagens possíveis para novas formas de subjetivação política, que reconfiguram a experiência comum e suscitam novos dissensos. Pois uma estética dissensual confronta a paisagem contemporânea consensual ao intervir numa determinada forma pré-estabelecida e hegemônica da partilha do sensível, sem levar à supressão conjunta da política e da arte pela ética da intenção do artista.

A partir da argumentação aqui desenvolvida, procurou-se elaborar uma problematização teórica para a crítica de arte que se volta a trabalhos de artistas que usam situações sociais para produzir projetos participativos e/ou colaborativos que são considerados de ponta, como uma 
espécie de vanguarda contemporânea. E que, paradoxalmente, são reconhecidos mais por seus nobres desejos em reduzir a política da arte à finalidade social e à indistinção ética do que pela consistência conceitual e estética de suas realizações. Assim, intenta-se colaborar para um renovado âmbito da reflexão estética como critério operativo na crítica de arte.

Artigo aceito pra publicação em dezembro de 2016.

\section{Notas}

1 O referido texto foi publicado em versão traduzida para o português pela revista Tatuí em 2011. Conferir referência na bibliografia.

\section{Referências}

ALBERRO, Alexander; SMITMSON, Blake (eds.). Conceptual art: a critical anthology. Cambridge: The MIT Press, 2000.

BENJAMIN, Walter. "O autor como produtor". In: Obras escolhidas: magia e técnica, arte e política. ed. 2. São Paulo: Brasiliense, 1986. BISHOP, Claire. "Antagonismo e estética relacional." In. Tatuí. Recife, n. 12, 2011, p. 109-132.

BISHOP, Claire. "A virada social: colaboração e seus desgostos". In. Concinnitas: Revista do Instituto de Artes da Uerj. Rio de Janeiro, julho 2008, ano 9, v.1, n 12, p. 143-155.

BOURRIAUD, Nicolas. Estética relacional. São Paulo: Martins Fontes, 2009.

BOURRIAUD, Nicolas. "Estética relacional, a política das relações". In: LAGNADO, Lisette, PEDROSA, Adriano [et al.]. $27^{a}$ Bienal de São Paulo: seminários (2006). São Paulo: Fundação Bienal de SP - Cobogó, 2008, p. 332-340.

CANCLINI, Néstor García. A Sociedade sem relato: antropologia e estética da iminência. São Paulo: Editora da Universidade de São Paulo (Edusp), 2012.

FOSTER, Hal. O retorno do real. São Paulo: Cosac Naify, 2014.

RANCIĖRE, Jacques. A partilha do sensível: estética e política. São Paulo: EXO experimental org; Ed. $34,2005$.

RANCIÈRE, Jacques. O espectador emancipado. São Paulo: Martins Fontes, 2012. 